Correspondence Anna A. Perevalova annprv@gmail.com

\section{Fervidicoccus fontis gen. nov., sp. nov., an anaerobic, thermophilic crenarchaeote from terrestrial hot springs, and proposal of Fervidicoccaceae fam. nov. and Fervidicoccales ord. nov.}

\author{
Anna A. Perevalova, ${ }^{1}$ Salima Kh. Bidzhieva, ${ }^{1}$ llya V. Kublanov, ${ }^{1}$ \\ Kai-Uwe Hinrichs, ${ }^{2}$ Xiaolei L. Liu, ${ }^{2}$ Andrey V. Mardanov, ${ }^{3}$ \\ Alexander V. Lebedinsky ${ }^{1}$ and Elizaveta A. Bonch-Osmolovskaya ${ }^{1}$
${ }^{1}$ Winogradsky Institute of Microbiology, Russian Academy of Sciences, Prospect 60-letiya Oktyabrya 7/2, 117312 Moscow, Russia
${ }^{2}$ Department of Geosciences and MARUM Center for Marine Environmental Sciences, University of Bremen, D-28334 Bremen, Germany
${ }^{3}$ Centre 'Bioengineering', Russian Academy of Sciences, Prospect 60-letiya Oktyabrya 7/1, 117312 Moscow, Russia

\begin{abstract}
Two novel thermophilic and slightly acidophilic strains, Kam $940^{\top}$ and Kam $1507 \mathrm{~b}$, which shared $99 \% 16$ S rRNA gene sequence identity, were isolated from terrestrial hot springs of the Uzon caldera on the Kamchatka peninsula. Cells of both strains were non-motile, regular cocci. Growth was observed between 55 and $85{ }^{\circ} \mathrm{C}$, with an optimum at $65-70{ }^{\circ} \mathrm{C}$ (doubling time, $6.1 \mathrm{~h}$ ), and at $\mathrm{pH}$ 4.5-7.5, with optimum growth at $\mathrm{pH}$ 5.5-6.0. The isolates were strictly anaerobic organotrophs and grew on a narrow spectrum of energy-rich substrates, such as beef extract, gelatin, peptone, pyruvate, sucrose and yeast extract, with yields above $10^{7}$ cells $\mathrm{ml}^{-1}$. Sulfate, sulfite, thiosulfate and nitrate added as potential electron acceptors did not stimulate growth when tested with peptone. $\mathrm{H}_{2}$ at $100 \%$ in the gas phase inhibited growth on peptone. Glycerol dibiphytanyl glycerol tetraethers (GDGTs) with zero to four cyclopentyl rings were present in the lipid fraction of isolate Kam940 ${ }^{\top}$. The $\mathrm{G}+\mathrm{C}$ content of the genomic DNA of strain Kam940 was $37 \mathrm{~mol} \%$. Phylogenetic analysis based on 16S rRNA gene sequences indicated that the isolates were archaea of the phylum Crenarchaeota, only distantly related to the cultured members of the class Thermoprotei (no more than $89 \%$ identity), and formed an independent lineage adjacent to the orders Desulfurococcales and Acidilobales and clustering only with uncultured clones from hot springs of Yellowstone National Park and Iceland as the closest relatives. On the basis of their phylogenetic position and novel phenotypic features, isolates Kam940 ${ }^{\top}$ and Kam1507b are proposed to be assigned to a new genus and species, Fervidicoccus fontis gen. nov., sp. nov. The type strain of Fervidicoccus fontis is strain Kam $940^{\top}$ $\left(=\mathrm{DSM} 19380^{\top}=\right.$ VKM B-2539 $\left.{ }^{\top}\right)$. The phylogenetic data as well as phenotypic properties suggest that the novel crenarchaeotes form the basis of a new family, Fervidicoccaceae fam. nov., and order, Fervidicoccales ord. nov., within the class Thermoprotei.
\end{abstract}

The Crenarchaeota are one of the two major phyla of the domain Archaea. Many crenarchaeotes have been isolated

Abbreviation: GDGT, glycerol dibiphytanyl glycerol tetraether.

The GenBank/EMBL/DDBJ accession number for the 16S rRNA gene sequence of strain $\mathrm{Kam} 940^{\top}$ is EF552404.

Details of sequences from other orders used in the construction of the trees shown in Fig. 2 are available as supplementary material with the online version of this paper. from hot marine and terrestrial environments (Huber \& Stetter, 2006). The Kamchatka peninsula is an active volcanic area where many terrestrial hot springs occur. The Uzon caldera is located in the east of Kamchatka and contains numerous active hydrothermal fields with a wide variety of chemical compositions, temperature and pH (Perevalova et al., 2008). Several organotrophic, anaerobic crenarchaeotes have been isolated from hot springs of Kamchatka, including Desulfurococcus amylolyticus 
(Bonch-Osmolovskaya et al., 1988), Thermoproteus uzoniensis (Bonch-Osmolovskaya et al., 1990b), Acidilobus aceticus (Prokofeva et al., 2000), Desulfurococcus fermentans (Perevalova et al., 2005), Vulcanisaeta strains (Prokofeva et al., 2005), Desulfurococcus kamchatkensis (Kublanov et al., 2009b) and Acidilobus saccharovorans (Prokofeva et al., 2009). All these organisms are hyperthermophiles, with optimum growth temperatures around $80-92{ }^{\circ} \mathrm{C}$. However, archaea, primarily representatives of uncultured lineages of Crenarchaeota, have also been found in terrestrial hot springs with temperatures that are too low $\left(55-75{ }^{\circ} \mathrm{C}\right.$ ) for hyperthermophiles (Pearson et al., 2004; Huang et al., 2007; Perevalova et al., 2008). Furthermore, in situ enrichment cultures obtained in the presence of various polymeric substrates from hot springs of the Uzon caldera at temperatures of $68-77^{\circ} \mathrm{C}$ demonstrated the presence of a novel group of Crenarchaeota (Kublanov et al., 2009a). Here, we report the isolation and characterization of two representatives of this novel group of Crenarchaeota that inhabit terrestrial hot springs and grow at temperatures around $70{ }^{\circ} \mathrm{C}$.

Samples of sediment mixed with water were collected from Treshchinnyi spring $\left(54^{\circ} 29^{\prime} 56.3^{\prime \prime} \mathrm{N} 160^{\circ} 00^{\prime} 55.9^{\prime \prime} \mathrm{E}\right)$ and Sery spring $\left(54^{\circ} 29^{\prime} 58^{\prime \prime} \mathrm{N} 160^{\circ} 00^{\prime} 50^{\prime \prime} \mathrm{E}\right)$ in the east thermal field of the Uzon caldera. The temperature and $\mathrm{pH}$ at the sampling sites were $80{ }^{\circ} \mathrm{C}, \mathrm{pH} 6.3$ and $75{ }^{\circ} \mathrm{C}, \mathrm{pH} 6.5$, respectively.

For enrichment cultures, anaerobically prepared basal medium (Perevalova et al., 2005) was used supplemented with $\left(1^{-1}\right) 1 \mathrm{mg}$ resazurin (Sigma), $1 \mathrm{ml}$ trace element solution (Pfennig \& Lippert, 1966), $1 \mathrm{ml}$ vitamin solution (Wolin et al., 1963) and $0.2 \mathrm{~g}$ yeast extract. After boiling, the medium was cooled under an atmosphere of $80 \% \mathrm{~N}_{2} /$ $20 \% \mathrm{CO}_{2}$ and supplemented with $0.5 \mathrm{~g} \mathrm{NaHCO}_{3}$ and $0.5 \mathrm{~g}$ $\mathrm{Na}_{2} \mathrm{~S} .9 \mathrm{H}_{2} \mathrm{O} \mathrm{l}^{-1}$, pH 6.0-6.5 (adjusted with $\mathrm{H}_{2} \mathrm{SO}_{4}$ ), and dispensed into $15 \mathrm{ml}$ Hungate tubes with butyl rubber stoppers, leaving $5 \mathrm{ml}$ headspace.

An aliquot $(10 \%)$ of the sediment/water mixture was incubated at $70{ }^{\circ} \mathrm{C}$ with chitin (crab chitin; Bioprogress) or $\beta$-keratin (ground feathers) at $2 \mathrm{~g} \mathrm{l}^{-1}$ and $\mathrm{pH}$ 6.0-6.5. After 3-5 days of incubation, organisms with regular coccoid cells were enriched. The enrichment cultures were designated $\mathrm{Kam} 940^{\mathrm{T}}$ and Kam1507b. For the isolation of strain $\mathrm{Kam} 940^{\mathrm{T}}$, the basal medium with peptone $\left(2 \mathrm{~g} \mathrm{l}^{-1}\right)$ was used, with the addition of $1.5 \%$ agar. Colonies were obtained in shake-tubes incubated at $60{ }^{\circ} \mathrm{C}$ after about a week. Individual colonies were picked and transferred to the same liquid medium without agar. Strain Kam1507b was isolated by the serial dilution-to-extinction method, using the basal medium with peptone. The purity of the isolates was tested by phase-contrast microscopy of cultures grown under various conditions. In pure cultures, all cells were single cocci.

Cells of both isolates were regular cocci, $1-3 \mu \mathrm{m}$ in diameter, without flagella (Fig. 1a). Thin sections (Bonch-Osmolovskaya et al., 1990a) revealed a cell
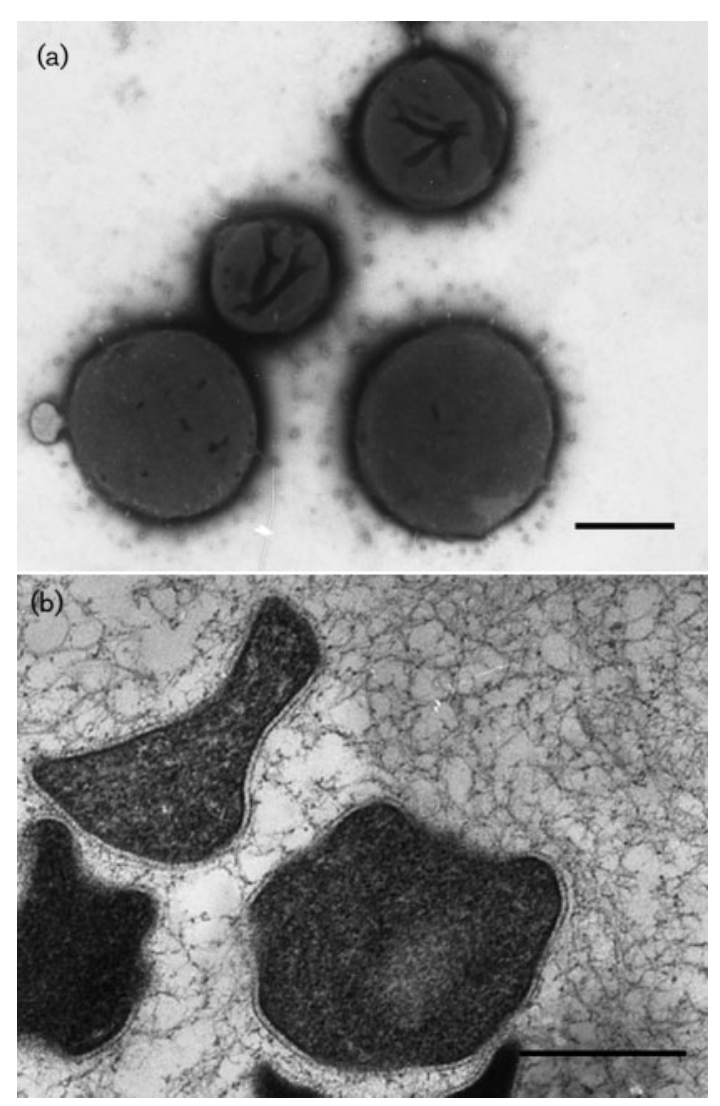

Fig. 1. Electron micrographs of negatively stained whole cells (a) and thin cell sections (b) of strain $\mathrm{Kam} 90^{\top}$. Bars, $1 \mu \mathrm{m}$.

envelope consisting of the cellular membrane covered with one layer of subunits (Fig. 1b).

Growth of the novel isolates was determined by direct cell counts using phase-contrast microscopy. All growth experiments were conducted in triplicate. Both isolates were obligate anaerobes, since no growth was observed under oxic conditions, as well as under anoxic conditions when the medium was not prereduced by the addition of sodium sulfide. The organisms were extreme thermophiles, growing in the temperature range of $55-85{ }^{\circ} \mathrm{C}$, with optimum growth at $65-70{ }^{\circ} \mathrm{C}$, and at $\mathrm{pH} 4.5-7.0$, with optimum growth at $\mathrm{pH}$ 5.5-6.0. No growth was observed at 53 or $89^{\circ} \mathrm{C}$ or at $\mathrm{pH} 4.0$ or 8.0 .

The nutritional spectrum of both strains was very narrow. Strains $\mathrm{Kam} 940^{\mathrm{T}}$ and Kam1507b grew by fermentation of beef extract, gelatin, peptone and yeast extract at $2 \mathrm{~g} \mathrm{l}^{-1}$, with final yields of $5.0 \times 10^{7}-8.5 \times 10^{7}$ cells $\mathrm{ml}^{-1}$. Weaker growth resulting in yields below $5.0 \times 10^{7}$ cells $\mathrm{ml}^{-1}$ was observed on albumin, amygdalin, arabinose, cellobiose, pyruvate, rhamnose, soy flour, sucrose and tryptone. No growth was detected on acetate, agarose, casein hydrolysate, chitin, cellulose (CM-cellulose and filter paper), dextran, glucose, fructose, fumarate, $\alpha$-keratin, lactate, maltose, mannitol, methanol, pectin, xylan or $\mathrm{H}_{2}$. Both 
strains required yeast extract (at a concentration of 20 $50 \mathrm{mg} \mathrm{l}^{-1}$ ). The final yield of strain $\mathrm{Kam} 940^{\mathrm{T}}$ on medium with yeast extract under optimal growth conditions was $8.4 \times 10^{7}$ cells $^{-1}$, with a doubling time of $6.1 \mathrm{~h}$. The growth products after growth on medium with sucrose, determined as described by Bonch-Osmolovskaya \& Miroshnichenko (1994), were acetate, $\mathrm{H}_{2}$ and $\mathrm{CO}_{2}$. The ability of strain $\mathrm{Kam} 940^{\mathrm{T}}$ to use electron acceptors was tested for the culture grown on peptone. Sodium thiosulfate and sodium nitrate (at $5 \mathrm{mM}$ ) were not reduced, whereas sodium sulfate and sodium sulfite inhibited growth. $\mathrm{H}_{2}$ (100\% in the gas phase) inhibited growth of strain Kam $940^{\mathrm{T}}$ completely on peptone.

Biomass of a culture of strain Kam $940^{\mathrm{T}}$ was lyophilized and used for lipid analysis. Total lipid extraction was performed using a single-phase organic solvent procedure and transesterified according to Pearson et al. (2004) and Zhang et al. (2006). HPLC-MS analysis of archaeal core lipids was performed at the University of Bremen, Germany, according to a modified procedure of Hopmans et al. (2000) on a ThermoFinnigan LCQ Deca XP Plus ion-trap mass spectrometer coupled to an HPLC by an atmospheric pressure chemical ionization interface. The instrument conditions are described in detail by Lipp \& Hinrichs (2009). The results showed that the majority (97\%) of the archaeal lipids were glycerol dibiphytanyl glycerol tetraethers (GDGTs) that contained zero to four cyclopentyl rings; the remaining small proportion $(3 \%)$ consisted of the diether archaeol. Of the five GDGT compounds, GDGT-0 was the most abundant (35.5\%), followed by GDGT-4 (19.2\%), GDGT-1 (15.8\%), GDGT-3 (13.8\%) and GDGT-2 (12.7\%). No crenarchaeol was present in the lipid fraction.

The G+C content of the DNA of strain Kam $940^{T}$ was determined by the thermal denaturation method (Marmur \& Doty, 1962) to be $37 \mathrm{~mol} \%$. 16S rRNA genes were amplified by PCR using the archaea-specific primer A8F (5'TCCGGTTGATCCTGCCGG-3') (Kolganova et al., 2002) as the forward primer and the universal primer S-D-Bact1492-a-A-21 (5'-TACGGYTACCTTGTTACGACTT-3') as the reverse primer (Alm et al., 1996). PCR products were sequenced using a Big Dye Terminator version 3.1 kit on an automatic ABI 3730 sequencer according to the manufacturer's protocol (Applied Biosystems). Sequences of the $23 \mathrm{~S}$ rRNA genes of strain Kam $940^{\mathrm{T}}$ and Acidilobus saccharovorans $345-15^{\mathrm{T}}$ were obtained in the course of complete genome sequencing of these organisms in the Centre 'Bioengineering' RAS. New sequences were used as queries for BLAST searches at the NCBI site (http://www.ncbi.nlm.nih.gov/blast; Altschul et al., 1997) for their preliminary identification and retrieval of similar sequences. The newly determined and retrieved sequences were aligned using the MULTALIN software (http://bioinfo.genopole-toulouse.prd.fr/multalin/) or MAFFT version 6 (http://align.genome.jp/mafft/). Pairwise evolutionary distances were calculated by using the correction of Jukes \& Cantor (1969). Phylogenetic trees were reconstructed using three different algorithms implemented in the
TREECONW software package version 1.3b (Van de Peer \& de Wachter, 1994). Since the tree topologies were very similar in all cases, the final results are presented as the neighbourjoining trees (Saitou \& Nei, 1987). Bootstrap analysis (1000 replications) was used to validate the reproducibility of the branching patterns of the trees.

Phylogenetic analysis based on 16S rRNA and 23S rRNA gene sequences placed the novel crenarchaeotes in the phylum Crenarchaeota as a novel, deep lineage adjacent to the orders Desulfurococcales and Acidilobales (Prokofeva et al., 2009) (Fig. 2). Strains Kam $940^{\mathrm{T}}$ and Kam1507b formed an independent cluster together with several uncultured clones from Yellowstone National Park (USA) and Iceland (Meyer-Dombard et al., 2005; Kvist et al., 2007; Perevalova et al., 2008). Of taxa with validly published names or any other reportedly cultured organisms, none exhibited more than $89 \%$ 16S rRNA gene sequence identity to strain Kam940 ${ }^{\mathrm{T}}$ or Kam1507b. On the basis of its phylogenetic position and novel phenotypic features, isolate Kam $940^{\mathrm{T}}$ is proposed as the type strain of a new genus and species, Fervidicoccus fontis gen. nov., sp. nov., which forms the basis of a new family, Fervidicoccaceae fam. nov., and order, Fervidicoccales ord. nov., within the class Thermoprotei of the phylum Crenarchaeota.

Environmental clones of the Fervidicoccus group have been found in terrestrial hot springs in different geographical regions with a broad range of temperatures (MeyerDombard et al., 2005; Kvist et al., 2007; Perevalova et al., 2008; Kublanov et al., 2009a). The phylotypes YNP_ObP_A25 and YNP_SSp_A51, found in Obsidian Pool and Sylvan Spring (Yellowstone National Park) with temperatures around $80{ }^{\circ} \mathrm{C}$, exhibit $94 \% 16 \mathrm{~S}$ rRNA gene sequence identity to strain $\mathrm{Kam} 940^{\mathrm{T}}$, and phylotypes from the Hveragerði region (Iceland), with temperatures of 55$81{ }^{\circ} \mathrm{C}$, Hverd031N (Kvist et al., 2007) and Is6 and V4 (Perevalova et al., 2008), exhibit 92-94\% 16S rRNA gene sequence identity to strain $\mathrm{Kam} 940^{\mathrm{T}}$. Furthermore, it was found that representatives of Fervidicoccus are widespread in terrestrial hot springs of the Uzon caldera with temperatures of $68-77^{\circ} \mathrm{C}$ (Kublanov et al., 2009a). The environments where Fervidicoccus clones were found are characterized by low contents of sulfide (Spear et al., 2005; Sun \& Armannsson, 2000; our unpublished results).

The majority of cultured crenarchaeotes are hyperthermophiles and neutrophiles. The more unusual extreme thermophiles with lower growth temperature optima are acidophiles and are predominantly aerobes or facultative anaerobes belonging to the Sulfolobales (Huber \& Prangishvili, 2006). Two novel aerobic, ammonia-oxidizing crenarchaeotes described by Hatzenpichler et al. (2008) and de la Torre et al. (2008) are also (extreme) thermophiles. Thermocladium modestius and the two species of Caldisphaera are the only known obligate anaerobes among the extremely thermophilic crenarchaeotes (Itoh et al., 1998, 2003; Boyd et al., 2007). Here, we report on a novel group of crenarchaeotes that grow optimally at tempera- 


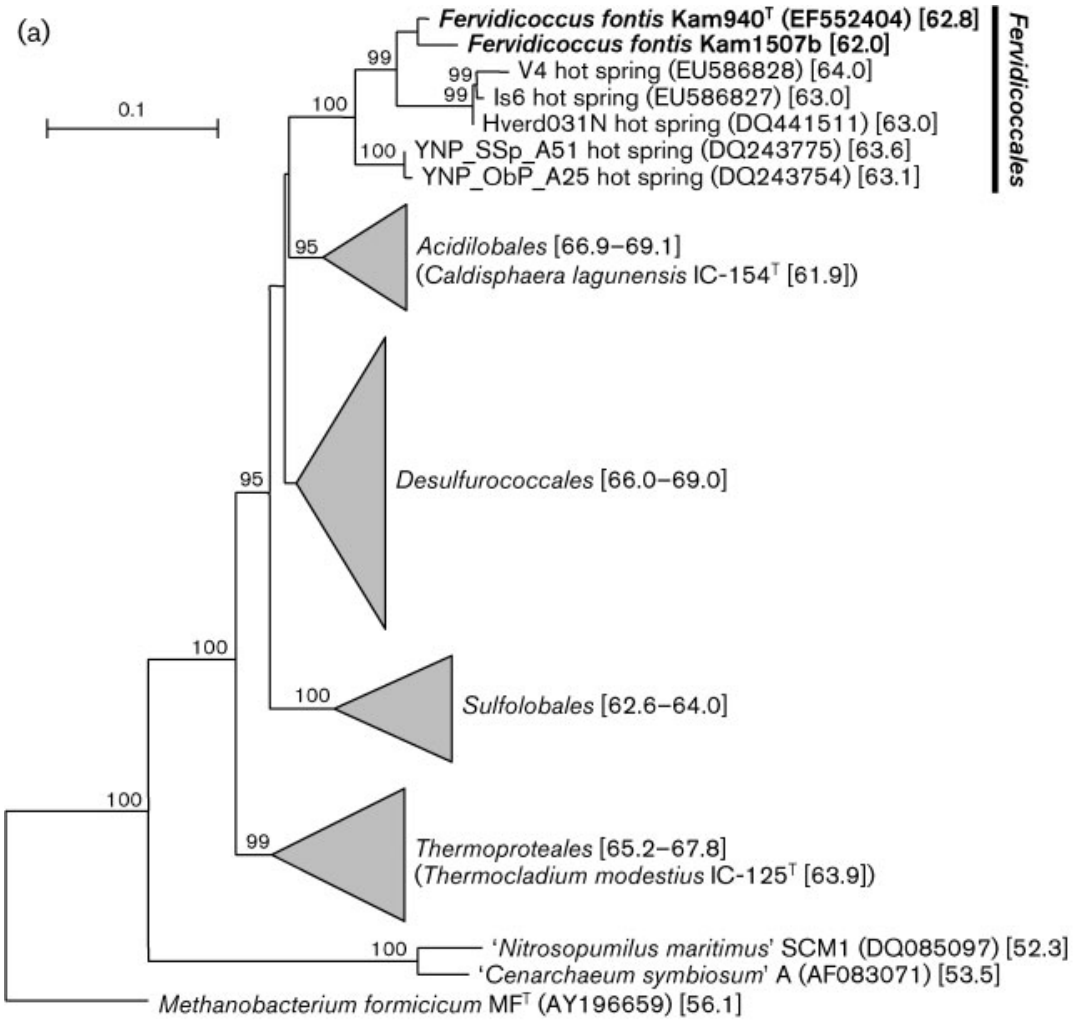

(b)

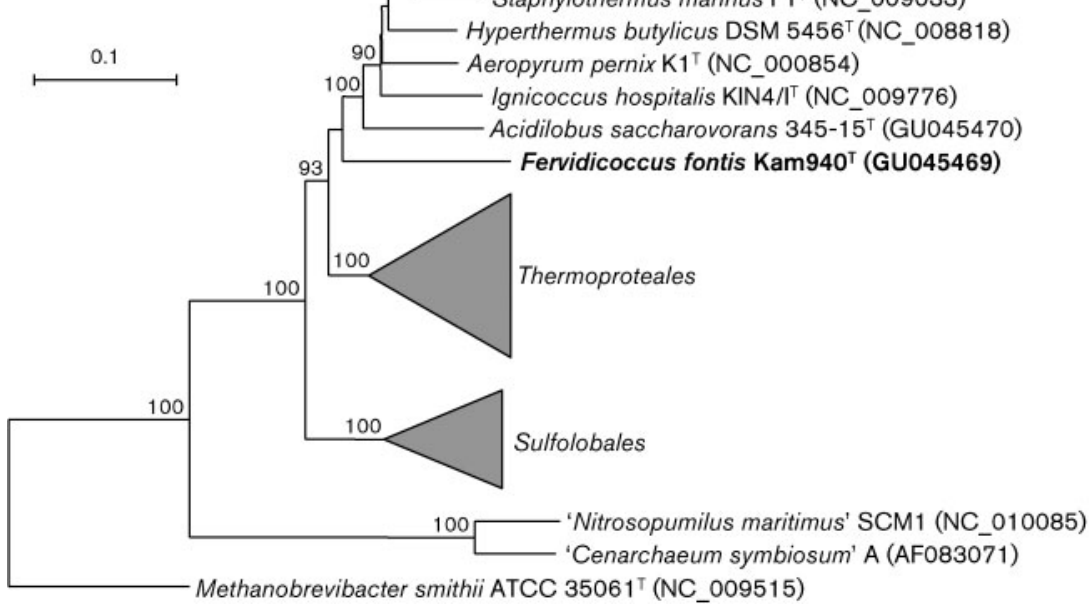

Fig. 2. Neighbour-joining phylogenetic trees based on 16S rRNA gene sequences (a) and 23S rRNA gene sequences (b) showing the positions of strains $\mathrm{Kam} 940^{\top}$ and Kam $1507 \mathrm{~b}$ (a) and strain $\mathrm{Kam} 940^{\top}$ (b) (Fervidicoccus fontis gen. nov., sp. nov.) within the phylum Crenarchaeota. Clusters of members of the orders Thermoproteales, Sulfolobales, Desulfurococcales and Acidilobales are indicated by triangles; sequences are detailed in Supplementary Table S1, available in IJSEM Online. Bootstrap values (from 1000 trials) of $90 \%$ and above are shown. GenBank accession numbers are given in parentheses. The $\mathrm{G}+\mathrm{C}$ contents of $16 \mathrm{~S}$ rRNA genes are shown in brackets in (a). Bars, 1 substitution per 10 sequence positions. tures $\left(65-70{ }^{\circ} \mathrm{C}\right)$ that are below the growth range of most cultured hyperthermophilic crenarchaeotes. The adaptation of the novel group of the Crenarchaeota to moderatetemperature habitats is evidenced by the $\mathrm{G}+\mathrm{C}$ contents of their 16S rRNA genes, known to correlate with the temperature growth optima of the organisms (Galtier \& Lobry 1997; Kimura et al., 2006). For example, the G+C contents of the 16S rRNA genes of hyperthermophilic crenarchaeotes are higher than $66 \mathrm{~mol} \%$ and, for comparison, that of marine non-thermophilic crenarchaeotes is around $53 \mathrm{~mol} \%$; extreme thermophiles have $16 \mathrm{~S}$ rRNA gene $\mathrm{G}+\mathrm{C}$ contents of $56-64 \mathrm{~mol} \%$. The $\mathrm{G}+\mathrm{C}$ content of the $16 \mathrm{~S}$ rRNA genes of isolates $\mathrm{Kam} 940^{\mathrm{T}}$ and $\mathrm{Kam} 1507 \mathrm{~b}$ and their relatives is $62-64 \mathrm{~mol} \%$ (Fig. 2a), which correlates with the temperature characteristics of their sources of isolation and with their temperature ranges for growth. The GDGT composition of strain Kam940 ${ }^{\mathrm{T}}$ also confirms the differences from other cultured hyperthermophilic crenarchaeotes. Cultured hyperthermophilic crenarchaeotes contain mostly GDGT-4 to -6 (Pearson et al., 2008), whereas the most abundant GDGT in strain $\operatorname{Kam} 940^{\mathrm{T}}$ is GDGT-0.

Considering the outlying position of the Fervidicoccus group in the phylogenetic trees (Fig. 2), the presence in the 16S rRNA of specific signatures (Table 1) and phenotypic 
Table 1. 16S rRNA sequence signatures that distinguish the Fervidicoccales ord. nov. from other orders of the phylum Crenarchaeota

Signatures were deduced from alignments retrieved from the GreenGenes database (updated 16 June 2008; 623 crenarchaeotal sequences). Sequence positions are given according to the Escherichia coli numbering. Fervidicoccales here refers to strain Kam $940^{\mathrm{T}}$ and environmental clones YNP_SSp_A51 and YNP_ObP_A25 (Hverd031N, Is6 and V4 sequences were too short for analysis). For all bases, the frequency was at least $97 \%$.

\begin{tabular}{|lcccc|}
\hline Position(s) & Fervidicoccales & Acidilobales & Desulfurococcales & Thermoproteales-Sulfolobales \\
\hline 34 & U & U & C & C \\
$501: 544$ & U-A & C-G & C-G & C-G \\
$1244: 1293$ & U-A & G-C & G-C & K-M, A-U \\
\hline
\end{tabular}

properties such as the temperature range and optimum, which distinguish representatives of this group from the phylogenetically adjoining members of the Desulfurococcales, we propose the taxonomic status of the Fervidicoccus group as being at the order level. The evolutionary divergence of this group may be related to adaptation to anaerobic environments in terrestrial hot springs with temperatures of $55-70{ }^{\circ} \mathrm{C}$.

\section{Description of Fervidicoccus gen. nov.}

Fervidicoccus (Fer.vi' di.coc'cus. L. adj. fervidus hot; L. masc. n. coccus a berry and, in biology, a coccoid cell; N.L. masc. n. Fervidicoccus coccus which grows at high temperatures).

Cells are regular cocci. Cell envelope consists of an S-layer covering the cytoplasmic membrane. Non-motile. Temperatures of $65-70{ }^{\circ} \mathrm{C}$ and slightly acidic $\mathrm{pH}$ (5.5-6.0) are preferred for growth. Obligately anaerobic. Organotrophic. Additional electron acceptors are not necessary. The $16 \mathrm{~S}$ rRNA gene sequence is typical of a crenarchaeote in sequence signature analysis. Phylogenetically, the genus represents an independent lineage. Known strains have been isolated from terrestrial hot springs. The type species is Fervidicoccus fontis.

\section{Description of Fervidicoccus fontis sp. nov.}

Fervidicoccus fontis (fon'tis. L. gen. masc. n. fontis of a spring or fountain, referring to the isolation of the type strain from a terrestrial hot spring).

Displays the following properties in addition to those in the genus description. Cells are $1-3 \mu \mathrm{m}$ in diameter. Grows at $55-85{ }^{\circ} \mathrm{C}$ and $\mathrm{pH} 4.5-7.0$. Growth occurs on beef extract, gelatin, peptone, pyruvate, rhamnose, sucrose and yeast extract with yields above $10^{7}$ cells $\mathrm{ml}^{-1}$. Sulfate, sulfite, thiosulfate and nitrate do not stimulate growth. $\mathrm{H}_{2}(100 \%)$ in the gas phase inhibits growth completely. The core lipid fraction consists of GDGTs with zero to four cyclopentyl rings. The DNA G $+\mathrm{C}$ content of the type strain is $37 \mathrm{~mol} \%$.

The type strain is $\operatorname{Kam} 940^{\mathrm{T}}$ (=DSM $19380^{\mathrm{T}}=\mathrm{VKM}$ B$2539^{\mathrm{T}}$ ), isolated from a hot spring of the east thermal field of the Uzon caldera, Kamchatka.

\section{Description of Fervidicoccaceae fam. nov.}

Fervidicoccaceae (Fer.vi'di.coc.ca'ce.ae. N.L. masc. n. Fervidicoccus the type genus of the family; -aceae ending to denote a family; N.L. fem. pl. n. Fervidicoccaceae the family of the genus Fervidicoccus).

Cocci. Anaerobic heterotrophs. Extreme thermophiles. Known habitats are terrestrial hot springs. The following pattern of 16S rRNA sequence signature nucleotides distinguishes the family Fervidicoccaceae: 34 (U), $501: 544$ (U-A), 1244 : 1293 (U-A). Members of the order Fervidicoccales in the class Thermoprotei. The type genus is Fervidicoccus.

\section{Description of Fervidicoccales ord. nov.}

Fervidicoccales (Fer.vi'di.coc.ca'les. N.L. masc. n. Fervidicoccus the type genus of the order; N.L. -ales ending to denote an order; N.L. fem. pl. n. Fervidicoccales the order of the genus Fervidicoccus).

The description is as for the family Fervidicoccaceae. The type genus is Fervidicoccus.

\section{Acknowledgements}

We are grateful to Nadezhda Kostrikina for the electron microscopy of the new isolate and to Nikolay Chernyh for determination of its DNA $\mathrm{G}+\mathrm{C}$ content. We thank Chuanlun Zhang and colleagues from Department of Marine Sciences, University of Georgia, for help with lipid analysis and Tatiana Kolganova (Centre 'Bioengineering', RAS) for providing $16 \mathrm{~S}$ rRNA gene sequences of the new isolates. This work was supported by the Russian Foundation for Basic Research, grant number 06-04-49045, and by the programs of the Russian Academy of Sciences 'Molecular and Cell Biology' and 'Origin and Evolution of the Biosphere' and the Federal Agency for Science and Innovations of Russia.

\section{References}

Alm, E. W., Oerther, D. B., Larsen, N., Stahl, D. A. \& Raskin, L. (1996). The oligonucleotide probe database. Appl Environ Microbiol 62, 3557-3559.

Altschul, S. F., Madden, T. L., Schaffer, A. A., Zhang, J., Zhang, Z., Miller, W. \& Lipman, D. J. (1997). Gapped BLAST and PSI-BLAST: a new generation of protein database search programs. Nucleic Acids Res 25, 3389-3402.

Bonch-Osmolovskaya, E. A. \& Miroshnichenko, M. L. (1994). The influence of molecular hydrogen and elemental sulfur on the 
metabolism of extremely thermophilic archaea of genus Thermococcus. Microbiology (English translation of Mikrobiologiia) 63, 433-437.

Bonch-Osmolovskaya, E. A., Slesarev, A. I., Miroshnichenko, M. L., Svetlichnaya, T. P. \& Alekseev, V. A. (1988). Characterization of Desulfurococcus amylolyticus n. sp. - a novel extremely thermophilic archaebacterium isolated from Kamchatka and Kurils hot springs. Mikrobiologiia 57, 94-101 (in Russian).

Bonch-Osmolovskaya, E. A., Sokolova, T. G., Kostrikina, N. A. \& Zavarzin, G. A. (1990a). Desulfurella acetivorans gen. nov. and sp. nov. - a new thermophilic sulfur-reducing eubacterium. Arch Microbiol 153, 151-155.

Bonch-Osmolovskaya, E. A., Miroshnichenko, M. L., Kostrikina, N. A., Chernyh, N. A. \& Zavarzin, G. A. (1990b). Thermoproteus uzoniensis sp. nov., a new extremely thermophilic archaebacterium from Kamchatka continental hot springs. Arch Microbiol 154, 556559.

Boyd, E. S., Jackson, R. A., Encarnacion, G., Zahn, J. A., Beard, T., Leavitt, W. D., Pi, Y., Zhang, C. L., Pearson, A. \& Geesey, G. G. (2007). Isolation, characterization, and ecology of sulfur-respiring Crenarchaeota inhabiting acid-sulfate-chloride-containing geothermal springs in Yellowstone National Park. Appl Environ Microbiol 73, 6669-6677.

de la Torre, J. R., Walker, C. B., Ingalls, A. E., Könneke, M. \& Stahl, D. A. (2008). Cultivation of a thermophilic ammonia oxidizing archaeon synthesizing crenarchaeol. Environ Microbiol 10, 810-818.

Galtier, N. \& Lobry, J. R. (1997). Relationships between genomic G + C content, RNA secondary structures, and optimal growth temperature in prokaryotes. J Mol Evol 44, 632-636.

Hatzenpichler, R., Lebedeva, E. V., Spieck, E., Stoecker, K., Richter, A., Daims, H. \& Wagner, M. (2008). A moderately thermophilic ammonia-oxidizing crenarchaeote from a hot spring. Proc Natl Acad Sci U S A 105, 2134-2139.

Hopmans, E. C., Schouten, S., Pancost, R. D., van der Meer, M. T. J. \& Sinninghe Damsté, J. S. (2000). Analysis of intact tetraether lipids in archaeal cell material and sediments by high performance liquid chromatography/atmospheric pressure chemical ionization mass spectrometry. Rapid Commun Mass Spectrom 14, 585-589.

Huang, Z., Hedlund, B., Wiegel, J., Zhou, J. \& Zhang, C. L. (2007). Molecular phylogeny of uncultivated Crenarchaeota in Great Basin hot springs of moderately elevated temperature. Geomicrobiol J 24, 535-542.

Huber, H. \& Prangishvili, D. (2006). Sulfolobales. In The Prokaryotes: a Handbook on the Biology of Bacteria, 3rd edn, vol. 3, pp. 23-51. Edited by M. Dworkin, S. Falkow, E. Rosenberg, K. H. Schleifer \& E. Stackebrandt. New York: Springer.

Huber, H. \& Stetter, K. O. (2006). Desulfurococcales. In The Prokaryotes: a Handbook on the Biology of Bacteria, 3rd edn, vol. 3, pp. 52-68. Edited by M. Dworkin, S. Falkow, E. Rosenberg, K. H. Schleifer \& E. Stackebrandt. New York: Springer.

Itoh, T., Suzuki, K. \& Nakase, T. (1998). Thermocladium modestius gen. nov., sp. nov., a new genus of rod-shaped, extremely thermophilic crenarchaeote. Int J Syst Bacteriol 48, 879-887.

Itoh, T., Suzuki, K., Sanchez, P. C. \& Nakase, T. (2003). Caldisphaera lagunensis gen. nov., sp. nov., a novel thermoacidophilic crenarchaeote isolated from a hot spring at Mt Maquiling, Philippines. Int $J$ Syst Evol Microbiol 53, 1149-1154.

Jukes, T. H. \& Cantor, C. R. (1969). Evolution of protein molecules. In Mammalian Protein Metabolism, vol. 3, pp. 21-32. Edited by H. N. Munro. New York: Academic Press.

Kimura, H., Sugihara, M., Kato, K. \& Hanada, S. (2006). Selective phylogenetic analysis targeted at 16S rRNA genes of thermophiles and hyperthermophiles in deep-subsurface geothermal environments. Appl Environ Microbiol 72, 21-27.

Kolganova, T. V., Kuznetsov, B. B. \& Turova, T. P. (2002). Designing and testing oligonucleotide primers for amplification and sequencing of archaeal 16S rRNA genes. Mikrobiologiia 71, 283-286 (in Russian).

Kublanov, I. V., Perevalova, A. A., Slobodkina, G. B., Lebedinsky, A. V., Bidzhieva, S. Kh., Kolganova, T. V., Rumsh, L. D., Haertle, T. \& Bonch-Osmolovskaya, E. A. (2009a). Biodiversity of thermophilic prokaryotes with hydrolytic activities in hot springs of Uzon Caldera, Kamchatka. Appl Environ Microbiol 75, 286-291.

Kublanov, I. V., Bidjieva, S. Kh., Mardanov, A. V. \& BonchOsmolovskaya, E. A. (2009b). Desulfurococcus kamchatkensis sp. nov., a novel hyperthermophilic protein-degrading archaeon isolated from a Kamchatka hot spring. Int J Syst Evol Microbiol 59, 1743-1747.

Kvist, T., Ahring, B. K. \& Westermann, P. (2007). Archaeal diversity in Icelandic hot springs. FEMS Microbiol Ecol 59, 71-80.

Lipp, J. S. \& Hinrichs, K.-U. (2009). Structural diversity and fate of intact polar lipids in marine sediments. Geochim Cosmochim Acta 73, 6816-6833.

Marmur, J. \& Doty, P. (1962). Determination of the base composition of deoxyribonucleic acid from its thermal denaturation temperature. J Mol Biol 5, 109-118.

Meyer-Dombard, D. R., Shock, E. L. \& Amend, J. P. (2005). Archaeal and bacterial communities in geochemically diverse hot springs of Yellowstone National Park, USA. Geobiology 3, 211-227.

Pearson, A., Huang, Z., Ingalls, A. E., Romanek, C. S., Wiegel, J., Freeman, K. H., Smittenberg, R. H. \& Zhang, C. L. (2004). Nonmarine crenarchaeol in Nevada hot springs. Appl Environ Microbiol 70, 52295237.

Pearson, A., Pi, Y., Zhao, W., Li, W., Li, Y., Inskeep, W., Perevalova, A., Romanek, C., Li, S. \& Zhang, C. L. (2008). Factors controlling the distribution of archaeal tetraethers in terrestrial hot springs. Appl Environ Microbiol 74, 3523-3532.

Perevalova, A. A., Svetlichny, V. A., Kublanov, I. V., Chernyh, N. A., Kostrikina, N. A., Tourova, T. P., Kuznetsov, B. B. \& BonchOsmolovskaya, E. A. (2005). Desulfurococcus fermentans sp. nov., a novel hyperthermophilic archaeon from a Kamchatka hot spring, and emended description of the genus Desulfurococcus. Int J Syst Evol Microbiol 55, 995-999.

Perevalova, A. A., Kolganova, T. V., Birkeland, N.-K., Schleper, C., Bonch-Osmolovskaya, E. A. \& Lebedinsky, A. V. (2008). Distribution of Crenarchaeota representatives in terrestrial hot springs of Russia and Iceland. Appl Environ Microbiol 74, 7620-7628.

Pfennig, N. \& Lippert, K. D. (1966). Über das Vitamin $B_{12}$-Bedürfnis phototropher Schwefelbakterien. Arch Mikrobiol 55, 245-246 (in German).

Prokofeva, M. I., Miroshnichenko, M. L., Kostrikina, N. A., Chernyh, N. A., Kuznetsov, B. B., Tourova, T. P. \& Bonch-Osmolovskaya, E. A. (2000). Acidilobus aceticus gen. nov., sp. nov., a novel anaerobic thermophilic archaeon from continental hot vents in Kamchatka. Int $J$ Syst Evol Microbiol 50, 2001-2008.

Prokofeva, M. I., Kublanov, I. V., Nercessian, O., Tourova, T. P., Kolganova, T. V., Lebedinsky, A. V., Bonch-Osmolovskaya, E. A., Spring, S. \& Jeanthon, C. (2005). Cultivated anaerobic acidophilic/ acidotolerant thermophiles from terrestrial and deep-sea hydrothermal habitats. Extremophiles 9, 437-448.

Prokofeva, M. I., Kostrikina, N. A., Kolganova, T. V., Tourova, T. P., Lysenko, A. M., Lebedinsky, A. V. \& Bonch-Osmolovskaya, E. A. (2009). Isolation of the anaerobic thermoacidophilic crenarchaeote Acidilobus saccharovorans sp. nov. and proposal of Acidilobales ord. nov., including Acidilobaceae fam. nov. and Caldisphaeraceae fam. nov. Int J Syst Evol Microbiol 59, 3116-3122. 
Saitou, N. \& Nei, M. (1987). The neighbor-joining method: a new method for reconstructing phylogenetic trees. Mol Biol Evol 4, 406-425.

Spear, J. R., Walker, J. J., McCollom, T. M. \& Pace, N. (2005). Hydrogen and bioenergetics in the Yellowstone geothermal ecosystem. Proc Natl Acad Sci U S A 102, 2555-2560.

Sun, Z. \& Armannsson, H. (2000). Gas chemistry and subsurface temperature estimation in the Hveragerði high-temperature geothermal field, SW-Iceland. In Proceedings of the World Geothermal Congress, pp. 2235-2240, 28 May-10 June 2000, Kyushu-Tohoku, Japan.
Van de Peer, Y. \& De Wachter, R. (1994). TREECON for Windows: a software package for the construction and drawing of evolutionary trees for the Microsoft Windows environment. Comput Appl Biol Sci 10, 569-570.

Wolin, E. A., Wolin, M. J. \& Wolfe, R. S. (1963). Formation of methane by bacterial extracts. J Biol Chem 238, 2882-2888.

Zhang, C. L., Pearson, A., Li, Y.-L., Mills, G. \& Wiegel, J. (2006). A thermophilic temperature optimum for crenarchaeol and its implication for archaeal evolution. Appl Environ Microbiol 72, 44194422 . 